\title{
Are immigrants' earnings influenced by the characteristics of their neighbours?
}

\author{
Sako Musterd \\ Department of Geography, Planning and International Development Studies, University of \\ Amsterdam, Nieuwe Prinsengracht 130, 1018 VZ Amsterdam, The Netherlands; \\ e-mail: s.musterd@uva.nl
}

\section{Roger Andersson}

Institute for Housing and Urban Research, Uppsala University, PO Box 785, SE-801 29 Gävle, Sweden; e-mail: roger.andersson@ibf.uu.se

\section{George Galster}

Department of Geography and Urban Planning, Wayne State University, Detroit, MI 48202, USA; e-mail: aa3571@Wayne.edu

\section{Timo M Kauppinen}

Department of Sociology, University of Helsinki, PO Box 18, FIN-00014 Helsinki, Finland; e-mail: timo.kauppinen@helsinki.fi

Received 23 March 2006; in revised form 13 June 2006; published online 11 February 2008

\begin{abstract}
Differences in immigrant economic trajectories have been attributed to a wide variety of factors. One of these is the local spatial context where immigrants reside. This spatial context assumes special salience in light of expanding public exposure to and scholarly interest in the potential impacts of spatial concentrations of immigrants. A crucial question is whether immigrants' opportunities are influenced by their neighbours. In this paper we contribute statistical evidence relevant to answering this vital question. We develop multiple measures of the spatial context in which immigrants reside and assess their contribution to the average earnings of immigrant individuals in the three large Swedish metropolitan areas, controlling for individual and regional labour-market characteristics. We use unusually rich longitudinal information about Swedish immigrants during the 1995-2002 period. We find evidence that immigrant men and women paid a substantial penalty during 1999-2002 if in 1999 they resided in areas where a substantial number of their neighbours were members of the same ethnic group. The evidence suggests that own-group concentrations can initially pay dividends for immigrants, but these benefits quickly turn into net disadvantages over time.
\end{abstract}

\section{Research and policy context}

The issue of immigration and the resulting ethnic concentrations in some metropolitan neighbourhoods has achieved a salient position in public discourse and policy discussions in Western Europe and the United States alike. In the United States this issue has taken on increased political significance as states and the federal government have considered and sometimes enacted legislative initiatives that would restrict immigration or limit types of social benefits to immigrants already living in the country (Preston et al, 1998). The popular justification for these initiatives is that many immigrants 'don't pull their own weight' and thus create 'fiscal burdens' (James et al, 1998). In Western Europe this issue is implicit in the widespread adoption of 'social mix' strategies wherein new housing development programmes and allocation schemes for social housing tenants have been tailored to minimize ethnic clustering (Andersson, 1998; 2001; Musterd, 2003; Musterd and Andersson, 2005). In some countries-not least in Sweden, which provides the empirical ground for this paper, but also in the Netherlands, Norway, and Denmark - refugee-dispersal policies are triggered by implicit and sometimes explicit views that the spatial concentration of immigrants is detrimental for their integration processes (Andersson, 2004). 
Some argue that differences in immigrant economic trajectories can be attributed primarily to intergroup variations in individual attributes such as human capital or values conducive to economic advancement. Others suggest the importance of factors well beyond the control of individual immigrants, such as variations in labour-market discriminatory barriers, political power structures, industrial restructuring, and the macroeconomic health of the metropolitan areas into which they migrated. Still others indicate that we merely need patience; as for waves of immigrants before them, the passage of time will permit most new immigrants to assimilate into the mainstream. Only relatively recently has there been consideration in this debate of the local spatial context of immigrant neighbourhoods and its potential effect on structuring opportunities.

In this paper we address the question: do concentrations of various ethnic groups in the environs aid or retard the chances for immigrants to improve their income? Though our study focuses on immigrants, it also contributes to the burgeoning, broader body of scholarship on 'area' or 'neighbourhood' effects (eg, Brooks-Gunn et al, 1997; Ellen and Turner, 2003; Friedrichs et al, 2005; Sampson et al, 2002). Virtually no prior work within this genre has attempted to operationalize the immigrant context of individuals' residential environments, or explore the impacts of a variety of coincident neighbourhood conditions on immigrants. The objectives of our investigation are to fill these gaps in the immigrant outcomes-neighbourhood effects literature by:

- Developing multiple measures of the spatial context in which Swedish immigrants reside, including the profiles of neighbours' immigrant and unemployment status, measured for a $500 \mathrm{~m} \times 500 \mathrm{~m}$ spatial grid centred on each individual.

- Assessing the contribution of spatial context variables to the earnings of immigrant individuals in the three largest Swedish metropolitan areas where they are most heavily concentrated, controlling for a wide range of individual and regional labour-market characteristics.

- Assessing the degree to which the contribution of spatial context to earnings may be generalized across seven immigrant groups regarded to be the most prominent in Sweden over the last couple of decades.

To accomplish these objectives, we conducted a multivariate regression analysis that was distinctive in three important ways. First, it utilized unusually rich information covering the entire population of the three largest metropolitan regions of Sweden at the individual level in a longitudinal way. This dataset allowed us to follow all Swedish immigrants individually during the 1995-2002 period. Second, because residence of each individual in Sweden is geocoded, we were able to construct ethnic and socioeconomic characteristics of $250000 \mathrm{~m}^{2}$ virtual spatial contexts, each centred on an individual immigrant. This permitted extremely detailed portraits of the ethnic and social spatial contexts surrounding immigrants to be constructed at a more finely grained scale than has heretofore been attempted. Third, the longitudinal nature of the data allowed us to develop a proxy for unmeasured individual characteristics that permitted us to purge estimated neighbourhood effects of selection bias.

\section{Spatial determinants of immigrants' socioeconomic advancement: an unsettled literature} Theoretical debates on the consequences of ethnic clustering

There have been numerous theoretical arguments advanced as to why certain ethnic or social environments have impacts on the economic success of immigrants. However, these arguments have been contradictory regarding whether ethnic spatial clusters provide net positive or negative opportunities for immigrant entrepreneurs or employees. 
Some have argued that groupings of specific ethnic businesses create benefits to immigrant employees from that ethnic group (Kloosterman and Rath, 2003; Portes, 1995). Ethnic businesses may provide more effective informal on-the-job training and apprenticeships (Portes and Zhou, 1992). Moreover, there may be less discrimination against prospective own-group employees because there will be less prejudice against them by coethnic employers and their expected clientele.

Entrepreneurs may also gain from colocation because ethnic goods that are available in spatial concentrations will attract more customers (Light and Rosenstein, 1995). Ethnic business clusters may also facilitate making so-called 'character loans' that are based on personal familiarity with the borrower (Portes and Zhou, 1992; Smith, 1995) and can create conduits for investments from nations of the immigrants' origin (Tseng, 1995; Yoon, 1995). Others have argued that higher productivity may ensue by clustering same-language workers in the workplace (Waldinger, 1996; 1997). Ethnic clusters may also benefit the development of trading niches unavailable to nonimmigrant entrepreneurs or niches left behind by other entrepreneurs (Kloosterman and Van der Leun, 1999).

The potential economic benefits from the residential clustering of immigrant households have been notably explored by Borjas $(1992 ; 1995 ; 1998)$ through his notion of 'ethnic capital', the average amount of human capital present in the preceding generation of the same ethnic group residing in the neighbourhood. He hypothesizes that children of immigrants will enjoy increased chances of economic success when they grow up in neighbourhoods having larger amounts of ethnic capital because they will receive better intergenerational transmissions of the local and human capital, norms for educational attainment, educational and job information, and employment opportunities. Other scholars have also cited the formation of social capital (Portes and Sensenbrenner, 1993; Portes and Zhou, 1992; 1993; Sanders and Nee, 1996; Smith, 1995; Waldinger, 1995; Waters, 1996a; 1996b) and denser networks for sharing job, educational, and other information (Aponte, 1996; Smith, 1995) as important benefits of ethnic residential clustering.

However, others have voiced a variety of cautions that suggest some potential disadvantages from ethnic clustering for employers and employees. Ethnic clusters may have little disposable income if located in an area of concentrated deprivation, thus inhibiting the growth potential of ethnic entrepreneurs (Clark and Drinkwater, 2002). In addition, excessive reliance by immigrant entrepreneurs on ethnic networks may hinder efforts to diversify supply chains and markets, thereby limiting profits and increasing vulnerability to shocks (Bates, 1994; Sanders and Nee, 1996). A further negative aspect of ethnic clustering may arise if personal contacts are limited to members of a class-homogeneous group from immigrants' own country of origin: 'bridging' social capital will be missing and social isolation can result (Waldinger, 1996). If the ethnic concentration completely serves all social and institutional needs, new immigrants may have less motivation to assimilate and develop host-country language and other skills (Massey and Denton, 1987). Finally, ethnic clusters may be stigmatized and discriminated against by powerful external actors controlling resources and opportunities (Wacquant, 1993).

\section{Statistical studies on the consequences of ethnic clustering}

It thus appears that there are no clear theoretical predictions about how ethnic clustering affects the economic prospects for those who live, work, and own businesses there. Unfortunately, only a few empirical studies have investigated directly with multivariate statistical models the impacts of various neighbourhood attributes on immigrant socioeconomic mobility, especially the presence of other immigrants. 
Borjas's (1995) analysis of immigrants in the US National Longitudinal Survey of Youth revealed that the percentage of population in the census tract that was of the same ethnicity as the observed persons when they were youths (ie in 1979) had a strong positive correlation with their 1990 educational attainment and wages, controlling for age, gender, first-generation or second-generation immigrant status, and parental skill levels. Follow-up work (Borjas, 1998) identified a positive correlation between an immigrant child's eventual educational attainment and that of adult neighbours whom they experienced during childhood, both those of the same ethnic group and, to a lesser degree, those in different ethnic groups. Thus, colocating with members of one's same immigrant group (especially if they are better educated), as well as with better educated neighbours of any ethnicity, seemed to promote positive economic outcomes subsequently.

Galster et al (1999) investigated the predictors of multiple measures of economic success during the 1980s of pre-1980 immigrants in fourteen ethnic groups in five large US metropolitan areas. Changes from 1980 to 1990 in the metrowide group mean values for seven education, occupation, labour force, and earnings outcome variables were regressed on multiple exposure indices showing the 1980 average presence of own-group residents, whites, those on public assistance, those not employed, and high-school dropouts in the group's neighbourhoods, with controls for metro-area changes and 1980 group socioeconomic status characteristics. Contrary to Borjas (1995; 1998), they found that exposure to more members of one's own immigrant group was associated with growing rates of poverty and lower gains in employment, on average for the group, during the subsequent decade. Though the group's exposure to high-school dropouts was not correlated with changes in school attainment, it attenuated the growth of those with professional-managerial occupations in the group, as Borjas would have predicted. Exposure to more nonemployed neighbours was associated with less growth in the group's rate of college graduation, but not with changes in any mean labour market outcomes.

Clark and Drinkwater (2002) analyzed individual 1993-94 survey data for ethnic minorities from England and Wales to see if four alternative labour-market statespaid employment, self-employment, unemployment, inactivity-were associated with own-ethnic characteristics of their residential ward in 1991, controlling for personal characteristics in a multinomial logit model. They found that the percentage of neighbours who were members of the minority individual's same ethnic group in 1991 significantly raised their risk of being unemployed in 1993-94, and reduced their chances of being self-employed.

Edin et al (2003) investigated neighbourhood effects for immigrants relocated across Sweden as part of a government-sponsored settlement plan and discovered decidedly mixed consequences. They found that living in municipalities with more members of the same ethnic group provided a substantial earnings gain to low-skill (not high-skill) immigrants, but only if the surrounding ethnic group in question had high incomes; otherwise, the earnings loss was substantial from locating in ethnic concentrations. After further analysis of these data, Aslund and Fredricksson (2005) found that welfare use among immigrants seemed to spill over into increased use by other immigrants of the same ethnicity living in the same municipality.

Van der Klaauw and van Ours (2003) examined whether individual transition rates from welfare to work in Rotterdam were influenced by a variety of neighbourhood measures including the percentage of non-Dutch residents. They found that neighbourhood effects, however measured, were not statistically significant predictors of exits from welfare for immigrants. 
In sum, extant empirical work reveals little that is consistent or definitive. There is some modest consensus that residing among poorly educated or not employed individuals retards the economic prospects of immigrants. But the direct tests of the effect of colocating among members of one's own ethnic group yield contradictory findings. It is this important gap that our research addresses.

\section{Empirical approach \\ Data sources}

Most of the variables we employ are constructed from data contained in the Statistics Sweden Louise files, which are produced annually. These files contain a large amount of longitudinal information on all individuals and represent compilations of data assembled from a range of statistical registers (income, education, labour market, and population). We have merged selected information about individuals from annual Louise files to create a longitudinal database 1995-2002 for all individuals aged 15 and above present in Sweden in 1995.

We emphasize that our dataset includes observations of virtually the entire population within our selected ethnic group members who immigrated by 1995 and had the desired adult age range, not a sample. Thus, the $t$-statistics we present below should not be interpreted as guides for prospective errors involving inferences from a sample to the larger population. Nevertheless, they provide useful information because we are attempting to assess the statistical strength of parameters estimated within the context of a particular multiple regression model of specified functional form having potential measurement errors in variables, not a simple population parameter. The $t$-statistics are thus appropriate means for evaluating the degree to which our estimated model reflects the 'true' model.

\section{Selection of immigrant ethnic groups for our analysis}

In this paper we analyze the ethnic clustering effects on seven immigrant groups: Bosnian, Chilean, Ethiopian, Iranian, Iraqi, Turkish, and Somalian. These immigrant groups are not only relatively numerous in the three metropolitan areas of Sweden but also residentially distributed within these areas in a very different fashion to Swedes (Anderson and Molina, 2003; Bråmå, 2006). Table 1 shows total numbers and distributions by year of immigration for the selected nationalities. The table shows only those included for our analysis, which means the metropolitan immigrant population. Of the total metropolitan population of the three areas involved, $16 \%$ is foreign born.

There is considerable variation across these groups on several dimensions. Bosnian immigrants are primarily post-Balkan-war refugees, who arrived in great numbers during

Table 1. Residency period for immigrants in Swedish metropolitan areas 1995-2002 with a special focus on selected nationalities (by country of birth).

\begin{tabular}{lrrrrrr}
\hline $\begin{array}{l}\text { Nationality } \\
\text { (country of birth) }\end{array}$ & \multicolumn{3}{l}{ Period in years $(\%)$} & \\
\cline { 2 - 6 } & $0-4$ & $5-9$ & $10-14$ & $15-19$ & $\geqslant 20$ & Total (no.) \\
\hline Bosnia & 97.4 & 0.5 & 0.3 & 0.3 & 1.6 & 11868 \\
Ethiopia & 26.6 & 46.8 & 11.3 & 8.0 & 7.4 & 6913 \\
Somalia & 82.8 & 13.7 & 2.1 & 1.2 & 0.1 & 4810 \\
Turkey & 15.2 & 19.9 & 18.8 & 27.8 & 18.3 & 16988 \\
Iraq & 59.0 & 22.3 & 16.0 & 2.1 & 0.6 & 13116 \\
Iran & 20.0 & 59.2 & 13.5 & 5.5 & 1.7 & 26286 \\
Chile & 6.7 & 42.7 & 19.2 & 25.9 & 5.6 & 13842 \\
Rest of the foreign born & 17.4 & 16.2 & 11.5 & 15.7 & 39.3 & 254510 \\
All foreign born & 22.4 & 20.9 & 12.0 & 14.5 & 30.2 & 348333 \\
\hline
\end{tabular}


the early 1990s under the regime of the Sweden-wide strategy aimed at dispersing refugees over the entire country (Andersson and Solid, 2003). Hence, many of them can still be found outside of the three metropolitan areas. The 1990s also saw the influx of Somali and Iraqi immigrants, who were mainly refugees. The Iranians mostly arrived around 1985, but this category also includes students trying to escape Iran even earlier. The Chilean category is a typical example of a Latin American political refugee group. They arrived in great numbers after the Pinochet coup in 1973. People from Turkey are in many ways the most heterogeneous category included in the analysis. They comprise labour migrants coming in the 1960s, (Christian) AssyrianSyrians arriving as refugees from the late 1960s onwards, and Kurdish minorities arriving over the last twenty-five years.

\section{Model for explaining individual incomes}

Our outcome of interest is the average annual income from work during 1999 and 2002. We analyze from our aforementioned seven ethnic groups only those who would be of working age during both 1999 and 2002 (ie, aged 16-58 in 1995) who were residents of Sweden in 1995 and present in one of Sweden's three major metropolitan areasStockholm, Gothenburg, and Malmö_in at least one year: 1995, 1999, or 2002. Since our average income measure encapsulates labour-force participation, employment regularity, and hourly compensation, we believe it to be the most comprehensive single measure of an individual's economic performance. We stress that this measure includes income from both wages and self-employment, so entrepreneurial activity is captured as well. Descriptive statistics for this outcome variable for our seven ethnic groups and for their aggregation as a whole are presented in table 2, stratified by gender.

We model income as a gender-specific and immigrant-group-specific, log-linear function of personal characteristics, of characteristics of the neighbourhood(s) in which they reside at the beginning of the period for which we measure earnings (1999) and four years prior, and of local labour-market conditions in 1999 and 2002. The log-linear transformation not only is appropriate given the positive skew of the income distribution, but also has sound grounding in economic theory, implicitly suggesting that income is an interactive (not additive) function of personal, neighbourhood, and labour-market characteristics. Symbolically:

$$
\begin{aligned}
\ln \left(I_{99-02 i j}\right)=\alpha+ & {\left[P_{95-02 i j}\right] \boldsymbol{\beta}+\left[P_{95 i j}\right] \boldsymbol{\gamma}+\left[U_{95 i j}\right] \lambda+\left[N_{95 i j}\right] \boldsymbol{\theta}+\left[N_{99 i j}\right] \boldsymbol{\phi} } \\
& +\left[L_{99-02 k j}\right] \boldsymbol{\mu}+\varepsilon,
\end{aligned}
$$

Table 2. Descriptive statistics for average labour income (100SEK) (1999 and 2002), by ethnic group and gender.

\begin{tabular}{lrrrrr}
\hline $\begin{array}{l}\text { Nationality } \\
\text { (country of birth) }\end{array}$ & \multicolumn{2}{l}{ Males } & & Females \\
\cline { 2 - 3 } \cline { 5 - 6 } & mean & $\begin{array}{c}\text { standard } \\
\text { deviation }\end{array}$ & & mean & $\begin{array}{c}\text { standard } \\
\text { deviation }\end{array}$ \\
\hline Bosnia & 1235.13 & 994.30 & & 871.06 & 808.50 \\
Ethiopia & 1236.21 & 1129.68 & & 1081.30 & 882.61 \\
Somalia & 624.70 & 739.32 & & 418.22 & 619.43 \\
Turkey & 1044.81 & 1062.89 & & 680.03 & 776.26 \\
Iraq & 894.70 & 1055.35 & & 604.95 & 776.01 \\
Iran & 1225.78 & 1293.14 & & 946.39 & 1001.82 \\
Chile & 1465.32 & 1240.73 & & 1159.99 & 880.76 \\
The seven groups & 1144.86 & 1160.93 & & 864.28 & 889.29
\end{tabular}


where

$I_{99-02}$ is the average annual income from work observed for the individual (1999 and 2002); ${ }^{(1)}$

$\left[P_{95-02}\right]$ are the observed personal characteristics that can vary over time (eg marital or fertility status, educational attainment);

$\left[P_{95}\right] \quad$ are the observed personal characteristics that do not vary after 1995 (eg year and country of birth, experiences prior to 1995);

$\left[U_{95}\right] \quad$ are unobserved personal characteristics that do not vary after 1995 that may affect both earnings and choice of neighbourhood in 1999;

$[N]$ are observed characteristics of the neighbourhood where the individual resides, in both 1995 and 1999 (ie own-group, other immigrants, unemployed);

[ $\left.L_{99-02}\right]$ are observed characteristics of regional labour market(s) in which the individual resides in 1999 and 2002 (eg mean earnings);

$\varepsilon \quad$ is the random error term with the usual assumed statistical properties;

$i \quad$ is gender;

$j \quad$ is ethnic immigrant group.

The Greek letters $\beta, \gamma, \lambda, \theta, \phi$, and $\mu$ represent vectors of parameters to be estimated through ordinary least squares (OLS) multiple regression techniques, with each regression stratified for a particular gender and ethnic group. Details of variable specifications follow.

We will examine the magnitudes of the neighbourhood variable coefficients $\boldsymbol{\theta}$ and $\boldsymbol{\phi}$ and their statistical significance across various ethnic groups as our central empirical focus. We will explore whether spatial context experienced by immigrants at the beginning of the period when incomes are measured (1999) and/or four years prior (1995) evinces different relationships with outcomes. This lag structure is also helpful in ensuring that any measured associations are indicative of causation running from neighbourhood context to subsequent income, and not vice versa.

The stratification by gender is required since earning an income and, behind that, participation in the labour market differ substantially by gender category and by ethnic group. The male/female labour-market participation ratio in the three metropolitan regions, as measured in November 1999, ranged between 0.95 for Ethiopians and 1.52 for Turkish inhabitants. If we focus the attention on female employed only, the percentage ranges from $78 \%$ for Swedes, through $61 \%$ for Chileans, $54 \%$ for Ethiopians, $28 \%$ for Iraqis, and $17 \%$ for Somali women. By undertaking the regression analyses separately for men and women, and for each immigrant group separately, we were able to consider a substantial number of interaction effects (with gender and immigrant category).

\section{Explanatory variables}

\section{Measures of neighbourhood context}

In this study we operationalize 'neighbourhood' as the area delineated by a (virtual) square, $500 \mathrm{~m}$ a side, positioned so that the observed individual resides in its centre. These 'neighbourhoods' were calculated for each immigrant. Thus, each individual at the same residential address has the same neighbourhood, but all people residing at different addresses have a different spatial designation of their neighbourhood. Since each individual's address in a given year is geocoded in our database, we can compute for both 1995 and 1999 the full population's characteristics within each immigrant's $250000 \mathrm{~m}^{2}$ surroundings. Of all individual environments $90 \%$ count more

(1) Income is computed here as the sum of: salary, income from business owned, and tax-based benefits accrued as terms of employment (sick or parental leave, work-related injury or illness compensation, daily payments for temporary military service, or giving assistance to a handicapped relative). 
than 500 residents. The characteristics of this set of people (excluding the individual immigrant in question) constitute the database for computing our eight neighbourhood variables (measured comparably for each immigrant's residence in both 1995 and 1999).

We measure the own-group composition of the neighbourhood with two variables: the percentage of adult residents who are members of the same national-origin group as the individual and the density of these same residents (expressed as adults per $\mathrm{km}^{2}$ ). The former variable is intended to measure the relative dominance of the immigrant's own group in the surrounding environment; the latter measures the likelihood of contact with members of this group (ie the density of their local own-group social networks). If ethnic clustering dynamics provide a net advantage for immigrants in Sweden, we would expect positive coefficients for both these variables.

We measure the overall immigrant status of the neighbourhood with two similar variables: the percentage of adult residents who are not Swedish born (including those in the individual's own group) and the density of these same residents (expressed as adults per $\mathrm{km}^{2}$ ). We employ these variables to explore how, after controlling for the number of own-group neighbours, the colocation of other-group immigrants affects the income prospects of the individual. If, controlling for numbers of own-group immigrants, larger total numbers of neighbouring immigrants (ie, meaning more from other ethnic groups) serve as better complements to the local economy of the given group (through, for example, boosting their entrepreneurs' labour demands or expanding the flow of information to their workers) than Swedish neighbours, we would expect to see positive coefficients for these variables. If, on the other hand, immigrants from other groups merely add competition, social strife, or greater chances for external stigmatization to the area, we would expect to see negative coefficients here.

Following on the work of Wilson (1987; 1996), Borjas (1995; 1998), and Galster et al (1999), another aspect of the spatial context that should matter is the average socioeconomic experience of an immigrant's neighbours, especially their connection with the labour market. We therefore compute a variable measuring the percentage of each individual's neighbours who are officially receiving unemployment benefits. But, as this percentage rises, we would expect that the efficacy of the local own-group and othergroup immigrant networks will be eroded. We thus add two variables to the model that measure the interaction of the percentage of unemployed in the neighbourhood with the aforementioned percentage of neighbours in the own-group and percentage of neighbours who are foreign born. We predict negative signs for all variables involving neighbourhood unemployment rates.

Finally, we control for the overall population density (expressed as persons per $\mathrm{km}^{2}$ ) of the neighbourhood. Density may serve as a proxy for a variety of factors that contribute to the economic prospects of residents. Higher density will increase the likelihood that an individual will come into incidental contact with a neighbour, thereby enhancing opportunities for social learning, role modelling, and information transmission. Density is also related to type of housing development in the vicinity, which may in turn relate to potential stigmatization of the area. We therefore have no predictions for the sign of this variable.

Descriptive statistics for these neighbourhood variables for our seven ethnic groups and for their aggregation were calculated. In table 3 we present the seven groups combined only.

We note several limitations with our neighbourhood measures. First, the virtual neighbourhood we computed may not always correspond well with boundaries of effective or functional neighbourhood. This potentially introduces random measurement error into key variables of interest and thus lowers their statistical significance. 
Table 3. Descriptive statistics for neighbourhood variables, seven ethnic groups combined.

\begin{tabular}{|c|c|c|c|c|c|c|}
\hline & \multicolumn{3}{|l|}{ Males } & \multicolumn{3}{|c|}{ Females } \\
\hline & mean & $\begin{array}{l}\text { standard } \\
\text { deviation }\end{array}$ & $\begin{array}{l}\text { maxi- } \\
\text { mum }\end{array}$ & mean & $\begin{array}{l}\text { standard } \\
\text { deviation }\end{array}$ & $\begin{array}{l}\text { maxi- } \\
\text { mum }\end{array}$ \\
\hline $\begin{array}{l}\text { Percentage own-ethnic group } 1995 \\
\quad(0-1 \text { scale })\end{array}$ & 0.046 & 0.053 & 1.00 & 0.049 & 0.053 & 1.00 \\
\hline $\begin{array}{l}\text { Percentage own-ethnic group } 1999 \\
\quad(0-1 \text { scale })\end{array}$ & 0.050 & 0.052 & 1.00 & 0.052 & 0.052 & 1.00 \\
\hline $\begin{array}{l}\text { Percentage immigrants } 1995 \\
\quad(0-1 \text { scale })\end{array}$ & 0.391 & 0.228 & 0.94 & 0.400 & 0.227 & 0.94 \\
\hline $\begin{array}{l}\text { Percentage immigrants } 1999 \\
\quad(0-1 \text { scale })\end{array}$ & 0.420 & 0.236 & 0.96 & 0.426 & 0.233 & 0.96 \\
\hline Population density per $\mathrm{km}^{2} 1995$ & 4820.9 & 3136.0 & & 4746.4 & 3038.9 & \\
\hline Population density per $\mathrm{km}^{2} 1999$ & 5365.4 & 3482.3 & & 5302.0 & 3358.0 & \\
\hline Immigrant density per $\mathrm{km}^{2} 1995$ & 2144.9 & 2108.8 & & 2187.7 & 2129.1 & \\
\hline Immigrant density per $\mathrm{km}^{2} 1999$ & 2510.5 & 2345.1 & & 2529.9 & 2330.2 & \\
\hline $\begin{array}{l}\text { Density of own-ethnic group per } \\
\mathrm{km}^{2} 1995\end{array}$ & 236.4 & 336.3 & & 250.6 & 347.5 & \\
\hline $\begin{array}{l}\text { Density of own-ethnic group per } \\
\mathrm{km}^{2} 1999\end{array}$ & 287.5 & 387.8 & & 294.5 & 386.3 & \\
\hline $\begin{array}{l}\text { Percentage unemployed } 1995 \\
\quad(0-1 \text { scale })\end{array}$ & 0.142 & 0.053 & & 0.142 & 0.051 & \\
\hline $\begin{array}{l}\text { Percentage unemployed } 1999 \\
\quad(0-1 \text { scale })\end{array}$ & 0.097 & 0.043 & & 0.096 & 0.042 & \\
\hline
\end{tabular}

Second, the scale of our neighbourhood may be too small to capture adequately the notion of an 'ethnic neighbourhood economy'. We can measure an ethnically dense $250000 \mathrm{~m}^{2}$, but not whether numerous such contiguous areas form a larger cluster. Third, we have no information about locations of ethnic businesses in our study, and thus can only partially operationalize the notion of 'ethnic neighbourhood economy' on the consumer-residential side.

\section{Control variables}

We operationalize the observed time-varying $\left[P_{95-02 i j}\right]$ and time-invariant $\left[P_{95 i j}\right]$ personal characteristics of individuals with a set of variables describing their demographic and household characteristics, educational attainments, length of residency in Sweden, and features of their employment during the period that will affect their income but are likely not related to neighbourhood context (such as parental leave or preretirement status). We operationalize $\left[L_{99-02 i j}\right]$ with the mean earnings for the local labour-market area in which the individual resided in 1999 and in 2002. Descriptive statistics for these control variables in the aggregate sample of all seven selected ethnic groups are presented for males and females in table 4.

Operationalizing unobserved, time-invariant characteristics of immigrants $\left[U_{95 i j}\right]$ requires further justification and explanation. Whenever one is interpreting statistical relationships between neighbourhood characteristics and individual outcomes, one must take care in ascribing causality because of potential selection bias (Galster, 2003; Manski, 2000). Is the observed statistical relationship between immigrant income and neighbourhood immigrant mix indicative of the neighbourhood's independent effect, or merely of unmeasured characteristics of immigrants (intelligence, diligence, etc) that truly affected their incomes but also (spuriously, in the extreme) led to neighbourhood choices as well? Indeed, the 'spatial assimilation' model (Massey, 1985) contends that immigrant economic success, assimilation, and residential location are mutually causal phenomena (though with a lag). 
Table 4. Descriptive statistics for control variables for seven ethnic groups combined, by gender.

$\begin{array}{llll}\text { Males } & & \text { Females } \\ { } } & \begin{array}{l}\text { standard } \\ \text { deviation }\end{array} & \text { mean } & \begin{array}{c}\text { standard } \\ \text { deviation }\end{array}\end{array}$

Number of children under age 7, 1995

Number of children, including $18+$ at home, 1995

Some sick leave during 1995 (1 = yes)

Preretired during 1995 ( $1=$ yes)

Parental leave during 1995 ( $1=$ yes $)$

Studying during 1995 ( $1=$ yes)

Number of children under age 7, 1999

Number of children, including $18+$ at home, 1999

Some sick leave during 1999 (1 = yes)

Preretired during 1999 ( 1 = yes)

Parental leave during 1999 ( $1=$ yes)

Studying during 1999 ( 1 = yes)

Number of children under age 7, 2002

Number of children, including $18+$ at home, 2002

Some sick leave during 2002 (1=yes)

Preretired during 2002 ( 1 = yes)

Parental leave during 2002 ( $1=$ yes $)$

Studying during 2002 ( $1=$ yes)

Years in Sweden

Age in years, 1995

Age at least 51 years, $1999(1=$ yes $)$

No formal education 1999 ( $1=$ yes $)$

$<10$ years education $1999(1=$ yes $)$

10 years education 1999 ( 1 = yes)

13 years, some postsecondary 1999 ( $1=$ yes $)$

$14+$ years but no PhD or licenciate $1999(1=$ yes $)$

$\mathrm{PhD}$ or licenciate attained $1999(1=$ yes $)$

Education rose $<11-12$ to $11-12+$, 1995-99

$$
\text { ( } 1 \text { = yes })
$$

Education rose $11-12$ to higher, 1995-99 ( $1=$ yes)

Education rose $<11-12$ to $11-12+, 1999-2002$

$$
\text { (1 = yes) }
$$

Education rose $11-12$ to higher, 1999-2002

$$
\text { (1 = yes) }
$$

Single 1995 but couple 1999 (1=yes)

Couple 1995 but single $1999(1=$ yes $)$

Single 1999 but couple 2002 (1 = yes)

Couple 1999 but single 2002 (1 = yes)

Mean income in local labour market, 1999 (100SEK)

Mean income in local labour market, 2002 (100SEK)

$\begin{array}{cccc}0.41 & 0.73 & 0.54 & 0.79 \\ 1.24 & 1.50 & 1.71 & 1.49 \\ 0.09 & 0.29 & 0.11 & 0.32 \\ 0.03 & 0.17 & 0.04 & 0.20 \\ 0.10 & 0.30 & 0.26 & 0.44 \\ 0.23 & 0.42 & 0.27 & 0.44 \\ 0.38 & 0.71 & 0.50 & 0.79 \\ 1.16 & 1.39 & 1.63 & 1.41 \\ 0.12 & 0.32 & 0.15 & 0.36 \\ 0.05 & 0.23 & 0.08 & 0.26 \\ 0.11 & 0.31 & 0.24 & 0.43 \\ 0.16 & 0.37 & 0.23 & 0.42 \\ 0.34 & 0.69 & 0.40 & 0.72 \\ 1.16 & 1.35 & 1.59 & 1.39 \\ 0.17 & 0.38 & 0.23 & 0.42 \\ 0.09 & 0.29 & 0.13 & 0.34 \\ 0.17 & 0.37 & 0.26 & 0.44 \\ 0.08 & 0.27 & 0.14 & 0.35 \\ 8.09 & 6.32 & 7.55 & 6.34 \\ 33.68 & 9.62 & 32.81 & 9.98 \\ 0.10 & 0.30 & 0.11 & 0.31 \\ 0.03 & 0.17 & 0.05 & 0.23 \\ 0.09 & 0.29 & 0.16 & 0.37 \\ 0.17 & 0.38 & 0.16 & 0.37 \\ 0.07 & 0.25 & 0.05 & 0.22 \\ 0.20 & 0.40 & 0.17 & 0.37 \\ 0.012 & 0.107 & 0.003 & 0.058 \\ 0.07 & 0.26 & 0.08 & 0.27 \\ 0.03 & 0.16 & 0.03 & 0.17 \\ 0.06 & 0.24 & 0.07 & 0.27 \\ & & & \\ 0.03 & 0.17 & 0.04 & 0.18 \\ 0.11 & 0.31 & 0.07 & 0.26 \\ 0.11 & 0.31 & 0.13 & 0.33 \\ 0.09 & 0.28 & 0.07 & 0.25 \\ 0.07 & 0.26 & 0.07 & 0.26 \\ 773.92 & 142.10 & 1776.77 & 140.60 \\ 0.93 & 164.50 & 2083.14 & 163.33\end{array}$

We addressed this potential problem in the following way. The worrisome unobserved characteristics of individuals cannot be measured directly, but should show up as prior labour-force performance that cannot be accounted for by observable characteristics. This can be measured by the residuals of a preliminary regression of labour earnings for 1995 that is virtually identical ${ }^{(2)}$ in specification to the regression (1). We add the values of these saved residuals produced by this regression as control variable $\left[U_{95 i j}\right]$ in equation (1).

(2) Because we have no information prior to 1991 we cannot compute the four-year lagged values of variables [equivalent to those measured in 1995 in equation (1)]. 


\section{Spatial econometric issues}

It is well-known that, if the error term $\varepsilon$ in equation (1) is spatially autocorrelated, an uncorrected OLS will yield biased and inconsistent estimates of parameters (Anselin, 1988). Our model effectively corrects for this problem by including a neighbourhood unemployment variable in the model that approximates a spatial lag. The formal correction for spatial autocorrelation would involve adding a spatial lag variable representing the weighted average of all earnings within a specified distance of the observed individual, with weights set a priori. We mimic this variable with our 'percentage unemployment in the neighbourhood' measure, which represents the average unemployment rate in the vicinity, with all those within a $250000 \mathrm{~m}^{2}$ space around the individual being weighted equally and those outside it given no weight.

\section{Empirical results}

\section{Immigrants' neighbourhoods in metropolitan Sweden}

As shown in table 3, Swedish immigrants in the last half of the 1990s did not typically live in places where their own ethnic group constituted a large share of the $250000 \mathrm{~m}^{2}$ area around them. On the contrary, in 1995 for all seven groups combined the mean percentage own-group was about $5 \%$ for both genders (ranging between $0.5 \%$ in the lowest decile to $12 \%$ in the highest decile), and the own-group density was 236 (for males) and 251 (for females) per $\mathrm{km}^{2}$. Nevertheless, we did observe some substantial clusters, as evinced by the fact that more than 5000 individual neighbourhoods have more than 500 residents and are characterized by a population in which at least $15 \%$ is of the individual's own ethnic group.

Immigrants from all groups did typically reside surrounded by large numbers of immigrants, however, with a 1995 mean of 39\% (for males) and 40\% (for females) immigrant neighbours and a density of immigrant neighbours of 2145 (for males) and 2189 (for females).

Overall, the neighbourhoods occupied by immigrants had higher rates of unemployment (14\% for both genders in 1995), compared with the overall unemployment rate in the three metropolitan areas investigated ( $9 \%$ for both genders in 1995). We speculate that, because of improving macroeconomic conditions, all groups saw their mean neighbourhood unemployment rates drop substantially from 1995 to 1999.

All the aforementioned statistics provide a context for interpreting our results. They are produced by a situation in which immigrants typically did not live predominantly with members of their own ethnic group, but typically did live among substantial numbers of immigrants. Moreover, their economic performance is observed during a period in which their neighbours' (and presumably their own) economic prospects were generally improving.

\section{Results of econometric modelling}

All of the results discussed below were generated by OLS multiple regression estimates of equation (1). We note that the reported standard errors are not biased upward due to clustering of individual observations at higher spatial scales, because here each address has a unique value for its surrounding virtual neighbourhood. Though multiple adults at the same address do indeed have common values for their neighbourhood variables, we do not see this as a significant source of bias in our estimated standard errors. Finally, we note that all models escaped multicollinearity, using conventional tests (Belsey et al, 1980).

\section{Patterns across all seven selected ethnic groups combined}

We begin by discussing the answer to our primary question regarding how the neighbourhood context of immigrants relates to their subsequent incomes by estimating 
equation (1) over adults in all seven of our ethnic groups combined, stratified by gender. These aggregate models produced $R^{2}$ of 0.35 for males and 0.42 for females, values typical for microlevel earnings studies. The control variables performed as per expectations and the interested reader can examine them in the appendix. Here we focus our discussion on the neighbourhood variables (see table 5).

Table 5. Regression results for neighbourhood variables, by gender, seven ethnic groups combined [dependent variable $=\ln$ (average income, 1999-2002)].

$\begin{array}{lll}t & p & \text { Standardized } \\ \beta & \end{array}$

\section{Males}

Percentage own ethnic group 1995

Percentage own ethnic group 1999

Percentage immigrants 1995

Percentage immigrants 1999

Population density per $\mathrm{km}^{2} 1995$

Population density per $\mathrm{km}^{2} 1999$

Immigrant density per $\mathrm{km}^{2} 1995$

Immigrant density per $\mathrm{km}^{2} 1999$

Density own-ethnic group per $\mathrm{km}^{2} 1995$

Density own-ethnic group per $\mathrm{km}^{2} 1999$

Percentage unemployed 1995

Percentage unemployed 1999

Percentage own-ethnic group $1995 \times$ percentage unemployed 1995

Percentage own-ethnic group $1999 \times$ percentage unemployed 1999

Percentage immigrants $1995 \times$ percentage unemployed 1995

Percentage immigrants $1999 \times$ percentage unemployed 1999

$\begin{array}{crrr}0.044 & 0.05 & 0.956 & 0.001 \\ -0.844 & -0.95 & 0.340 & -0.015 \\ -0.259 & -1.02 & 0.306 & -0.020 \\ 0.108 & 0.47 & 0.636 & 0.009 \\ -0.000017 & -2.30 & 0.022 & -0.018 \\ -0.000034 & -5.27 & 0.000 & -0.040 \\ -0.000029 & -1.40 & 0.161 & -0.021 \\ 0.000072 & 3.61 & 0.000 & 0.058 \\ 0.000446 & 4.62 & 0.000 & 0.051 \\ -0.000367 & -3.82 & 0.000 & -0.049 \\ -1.132 & -2.40 & 0.016 & -0.020 \\ 0.830 & 1.26 & 0.209 & 0.012 \\ 4.707 & 1.23 & 0.220 & 0.016 \\ & & & \\ 8.954 & 1.56 & 0.119 & 0.022 \\ & & & \\ 1.199 & 0.91 & 0.365 & 0.020 \\ -7.792 & -5.22 & 0.000 & -0.102\end{array}$

$R^{2}=0.351$

\section{Females}

Percentage own ethnic group 1995

Percentage own ethnic group 1999

Percentage immigrants 1995

Percentage immigrants 1999

Population density per $\mathrm{km}^{2} 1995$

Population density per $\mathrm{km}^{2} 1999$

Immigrant density per $\mathrm{km}^{2} 1995$

Immigrant density per $\mathrm{km}^{2} 1999$

Density own ethnic group per $\mathrm{km}^{2} 1995$

Density own ethnic group per $\mathrm{km}^{2} 1999$

Percentage unemployed 1995

Percentage unemployed 1999

Percentage own ethnic group $1995 \times$ percentage unemployed 1995

Percentage own ethnic group $1999 \times$ percentage unemployed 1999

Percentage immigrants $1995 \times$ percentage unemployed 1995

Percentage immigrants $1999 \times$ percentage unemployed 1999

$\begin{array}{crrr}2.071 & 2.24 & 0.025 & 0.035 \\ -2.712 & -2.87 & 0.004 & -0.045 \\ -0.044 & -0.15 & 0.880 & -0.003 \\ 0.228 & 0.87 & 0.384 & 0.017 \\ -0.000025 & -2.74 & 0.006 & -0.024 \\ -0.000022 & -2.74 & 0.006 & -0.023 \\ 0.000025 & 1.01 & 0.311 & 0.017 \\ 0.000051 & 2.17 & 0.030 & 0.038 \\ 0.000023 & 0.21 & 0.834 & 0.003 \\ -0.000250 & -2.25 & 0.024 & -0.031 \\ 0.713 & 1.30 & 0.195 & 0.012 \\ -0.118 & -0.15 & 0.878 & -0.002 \\ -3.955 & -0.95 & 0.342 & -0.013 \\ & & & \\ 6.828 & 1.26 & 0.209 & 0.016 \\ -0.319 & -0.21 & 0.834 & -0.005 \\ & & & \\ -5.760 & -3.42 & 0.001 & -0.071\end{array}$

$R^{2}=0.422$ 
Of prime interest are estimates for variables related to ethnic concentrations. The relationships observed between 1995 own-group concentration and incomes 1999-2002 are generally positive for both genders. The positive coefficient of percentage owngroup for immigrant women and the positive coefficient of density of own-group for immigrant men are statistically significant.

However, 1999 residence in a neighbourhood with higher numbers of own-group members is negatively related to subsequent income for both male and female immigrants. The negative coefficients of density of own-group in 1999 are highly statistically significant for both genders, and the negative coefficients for percentage of own-group are significant for females and approximately the size of the standard error for males.

These findings are provocative when we combine the aforementioned results for the 1995 and 1999 variables, for they suggest negative persistence effects from ethnic colocation. The results are consistent with the notion that ethnic concentrations can provide positive environments for coethnic workers and entrepreneurs to develop skills, credentials, attitudes, behaviours, and/or contacts that can pay off in higher incomes a half decade or more later. However, the implicit negative aspects of the ethnic concentrations apparently grow the longer one resides there. If this negative persistence effect is assumed to be linear over time, the difference between (statistically significant) coefficient magnitudes of 1995 and 1999 own-group variables implies that the net value of the ethnic concentration to the individual turns negative after roughly two years of residence for women and men alike.

The results for the number of immigrants from all backgrounds in the neighbourhood in 1999 are also intriguing, for they strongly suggest that this number has a negative impact on the incomes of an individual from a different ethnic group unless almost everyone in the neighbourhood is employed. This is seen by an examination of the statistically significant positive coefficient for immigrant density in 1999 in conjunction with the statistically significant negative coefficients for this variable interacted with unemployment rate in the neighbourhood, which are comparable for both genders. Mathematical manipulation of the coefficients reveals that the main (positive) relationship appertains so long as the unemployment rate does not exceed $2.7 \%$ in males' case and $3.5 \%$ in females' case. This means that, unless unemployment in the current neighbourhood is at a very low level, the individual's income over the next four years will be lower the greater the number of immigrants there are in the neighbourhood. Because the number of own-group immigrants is being controlled, this result can be interpreted as an impact from immigrants in other groups. Put differently, it seems as if employed immigrant neighbours offer something of near-term value to the immigrant even when they are of a different ethnicity, such as - perhaps-information about better jobs or business connections. This turns to a net negative, however, when they are unemployed.

The final noteworthy result regarding neighbourhood effects is that the overall population density in both 1995 and 1999 is negatively related to average income 1999-2002 in a statistically significant fashion for both male and female immigrants. This is consistent with a neighbourhood effect transmitted by external stigmatization based on housing type or density of the area, although the magnitude of the implied impacts is considerably smaller than that associated with own-group composition of the area.

\section{Distinctions among ethnic groups}

We now turn to a brief assessment of the degree to which the aforementioned contributions of spatial context to earnings may be generalized across the seven main Swedish immigrant groups we consider here. Most of the patterns discussed above 
may indeed be generalized across several ethnic groups, although in the stratified regressions the number of statistically significant coefficients is attenuated.

The apparent negative impacts of larger numbers of one's own group in the neighbourhood persist, with one exception. With regard to male immigrants, the aggregate patterns are mirrored most strongly by Bosnians, but significant negative relationships are evinced for Iranian and Somalian males as well. Interestingly, these groups are the ones that have arrived in Sweden most recently (see table 1). The same relationships hold for Bosnian and Iranian female immigrants, but not for Somalian females. On the contrary, they evince the only example (in either gender) of a statistically significant positive association between own-group and income.

In the case of total immigrants in the neighbourhood, the positive main effects observed in the aggregate regressions persist broadly; this occurs for Chilean, Somalian, and Iraqi men and for Bosnian women. Iranian men, however, evince a significantly negative relationship between total immigrants in the neighbourhood and their income. Unlike the aggregate regressions, however, in none of the group-specific runs do the negative interaction effects with unemployment appear statistically significant. We thus cannot be confident in the robustness of the dependence of the effect of other nearby immigrants on the neighbourhood's unemployment rate.

\section{Are effects of ethnic clusters economically important? Some simulations}

We now use the results from the models shown in table 5 to illustrate the neighbourhood effects in terms of Swedish Kroner (SEK) to get a more intuitive sense of the magnitude of the relationships. The first illustration concerns the positive effects of percentage and density of own-group neighbours in 1995. Since a hypothetical change in the number of own-group neighbours mathematically affects both percentage and density variables, we can combine their results in the simulation. Assume that two hypothetical, otherwise-identical urban female immigrants resided in 1995 in two neighbourhoods both consisting of 500 adults (close to our sample median of 580) and otherwise identical, but they differ because one is a standard deviation above the mean for own-group share and the other is one standard deviation below. The first neighbourhood had no own-group members whereas the second had $50(10 \%)$. The estimated parameters indicate that the immigrant woman in the second neighbourhood would be expected to earn 24000 SEK more per year over the next four years. The comparable exercise conducted for immigrant males produces a much smaller estimate, 10000 SEK more. ${ }^{(3)}$

The second simulation is for the negative effects of percentage and density of owngroup neighbours in 1999. Again assume that two hypothetical, otherwise-identical urban female immigrants resided in 1999 in two neighbourhoods both consisting of 500 adults and otherwise identical, but the first neighbourhood had no own-group members whereas the second had $50(10 \%)$. The estimated parameters indicate that the immigrant woman in the second neighbourhood would be expected to earn 27000 SEK less per year over the next four years, a substantial amount indeed. The comparable exercise conducted for immigrant males produces a much smaller estimate, 15000 SEK less, even if the statistically insignificant point estimate for percentage own-group is also used.

Next, we simulate the effect of percentage of all immigrants in 1999 and how it depends on the unemployment rate. As before, we can get a sense of the magnitude of these relationships using the aforementioned 1999 hypothetical neighbourhoods of 500 people, let them differ only in that one is a standard deviation above the mean for all immigrants and the other is one standard deviation below. The first has

(3) In these examples, the hypothetical individual earns 100 000SEK when the neighbourhood variables have zero values. 
85 immigrants $(17 \%)$ and the second has 315 immigrants $(63 \%)$ of a different group than the individual. Now, if there were no unemployed adults in either neighbourhood, only the main positive effect would be operative. In this case, the immigrant male (female) would be predicted to earn 13 000SEK (17000SEK) more in the immigrantrich neighbourhood. However, with even a small amount of assumed unemployment in these two neighbourhoods, say $5 \%$, the positions are reversed: the immigrant male would be predicted to earn 6000SEK less in the immigrant-rich neighbourhood. Females would still earn a little bit more (2000SEK). These differences would be magnified were we to assume a more deprived pair of neighbourhoods, such as an unemployment rate of $20 \%$. Then the immigrant male (female) would be predicted to earn 43 000SEK (27000SEK) less in the immigrant-rich neighbourhood.

\section{Conclusions}

We have investigated the labour-income impacts of the spatial concentration of immigrants on their immigrant residents, analyzing adults from seven major ethnic groups in metropolitan Sweden. We have found that both immigrant men and women paid a substantial income penalty during 1999-2002 if in 1999 they resided in areas where a substantial number of their neighbours (within a $250000 \mathrm{~m}^{2}$ area) were members of the same ethnic group. These relationships are most consistent among members of the immigrant groups who arrived most recently. The evidence suggests that own-group concentrations can initially pay dividends for immigrants with less tenure in Sweden, but that these benefits quickly turn into net disadvantages over time. The only apparent exception to this generalization seems to be Somali women. This is consistent with the conclusions drawn from statistical studies undertaken with US and English data (Clark and Drinkwater, 2002; Galster et al, 1999).

The impact of immigrant neighbours from other ethnic groups appears to be quite different, however. Their impact is positive in neighbourhoods where everyone is employed. However, with even modest amounts of unemployment in the neighbourhood the presence of more immigrants severely harms the income prospects of individual immigrants from different groups. Why these relationships are evinced should be the focus of additional investigations into these immigrant-dense communities.

We believe that our distinctive analysis sample, neighbourhood measures, and control for selection bias produce strong results that add still more weight to the mounting international conclusion that the local residential environment substantially structures one's opportunities for economic success (Galster and Killen, 1995). As such, it keeps the issue of neighbourhood conditions squarely on the front burner of public policy concerns over ethnicity, opportunity, and inequality.

Acknowledgements. We thank Michiel Musterd for this computer programming contributions. We also thank Julia Koschinsky for spatial econometric advice and anonymous referees for their constructive suggestions on an earlier draft.

\section{References}

Andersson R, 1998, "Socio-spatial dynamics: ethnic divisions of mobility and housing in post-Palme Sweden" Urban Studies $35397-428$

Andersson R, 2001, "Spaces of socialisation and social network competition: a study of neighbourhood effects in Stockholm, Sweden", in Social Exclusion, Social Fragmentation and Urban Governance Eds H T Andersen, R van Kempen (Ashgate, Aldershot, Hants) pp 149-188

Andersson R, 2004, "Settlement dispersal of immigrants and refugees in Europe: policy and outcomes", paper for the 6th National Metropolis Conference, Edmonton, Canada, 21 - 24 March, WP 03-08, Research on Immigration and Integration in the Metropolis, http://www.riim.metropolis.net 
Andersson R, Molina I, 2003, "Racialization and migration in urban segregation processes: key issues for critical geographers", in Voices from the North Eds K Simonsen, J Öhman (Ashgate, Aldershot, Hants) pp $261-282$

Andersson R, Solid D, 2003, "Dispersal policies in Sweden", in Spreading the 'Burden?'A Review of Policies to Disperse Asylum Seekers and Refugees Eds V Robinson, R Andersson, S Musterd (Policy Press, Bristol) pp 65-102

Anselin L, 1988 Spatial Econometrics: Methods and Models (Kluwer Academic, Dordrecht)

Aponte R, 1996, "Urban employment and the mismatch dilemma: accounting for the immigration exception" Social Problems $\mathbf{4 3} 268-283$

Aslund O, Fredricksson P, 2005, "Ethnic enclaves and welfare cultures: quasi-experimental evidence", unpublished manuscript, Department of Economics, Uppsala University

Bates T, 1994, "Social resources generated by group support networks may not be beneficial to Asian immigrant-owned businesses" Social Forces 72 671-689

Belsey D A, Kuh E, Welsch R E, 1980 Regression Diagnostics (John Wiley, New York)

Borjas G, 1992, "Ethnic capital and intergenerational mobility" Quarterly Journal of Economics $85365-490$

Borjas G, 1995, "Ethnicity, neighbourhoods, and human capital externalities" American Economic Review 85365 - 390

Borjas G, 1998, "To ghetto or not to ghetto: ethnicity and residential segregation" Journal of Urban Economics $44228-253$

Bråmå Å, 2006, "Studies in the dynamics of residential segregation", Geografiska Region-Studier 67 Uppsala Universitet, Uppsala

Brooks-Gunn J, Duncan G, Aber J L (Eds), 1997 Neighborhood Poverty (Russell Sage Foundation, New York)

Clark K, Drinkwater S, 2002, "Enclaves, neighbourhood effects and employment outcomes: ethnic minorities in England and Wales" Journal of Population Economics 15 - 29

Edin P, Fredricksson P, Aslund O, 2003, "Ethnic enclaves and the economic success of immigrants: evidence from a natural experiment" Quarterly Journal of Economics 113329 - 357

Ellen I G, Turner M A, 2003, "Do neighborhoods matter and why?", in Choosing a Better Life? Evaluating the Moving To Opportunity Experiment Eds J Goering, J Feins (Urban Institute Press, Washington, DC) pp $313-338$

Friedrichs J, Galster G, Musterd S (Eds), 2005 Life in Poverty Neighbourhoods; European and American Perspectives (Routledge, London)

Galster G, 2003, "Investigating behavioral impacts of poor neighborhoods: towards new data and analytic strategies" Housing Studies 18893 -914

Galster G, Killen S, 1995, "The geography of metropolitan opportunity: reconnaissance and conceptual framework" Housing Policy Debate 6 7-44

Galster G, Metzger K, Waite R, 1999, "Neighborhood opportunity structures and immigrants' socioeconomic advancement" Journal of Housing Research $1095-127$

James F J, Romine J A, Zwanzig P E, 1998, “The effects of immigration on urban communities" Cityscape $3171-192$

Kloosterman R, Rath J, 2003 Immigrant Entrepreneurs: Venturing Abroad in the Age of Globalization (Berg, Oxford)

Kloosterman R, van der Leun J, 1999, "Just for starters: commercial gentrification by immigrant entrepreneurs in Amsterdam and Rotterdam neighbourhoods" Housing Studies 14 659-677

Light I, Rosenstein C, 1995, "Expanding the interaction theory of entrepreneurship", in The Economic Sociology of Immigration Ed. A Portes (Russell Sage Foundation, New York) pp $166-212$

Manski C F, 2000, "Economic analysis of social interactions" Journal of Economic Perspectives $14115-136$

Massey D, 1985, "Ethnic residential segregation: a theoretical and empirical review" Sociology and Social Research $69315-350$

Massey D, Denton N, 1987, "Trends in residential segregation of Blacks, Hispanics, and Asians" American Sociological Review $52802-825$

Musterd S, 2003, "Segregation and integration: a contested relationship" Journal of Ethnic and Migration Studies $29623-641$

Musterd S, Andersson R, 2005, "Housing mix, social mix and social opportunities" Urban Affairs Review $40761-790$

Portes A, 1995 The Economic Sociology of Immigration: Essays on Networks, Ethnicity, and Entrepreneurship (Russell Sage Foundation, New York) 
Portes A, Sensenbrenner J, 1993, "Embeddedness and immigration: notes on the social determinants of economic action" American Journal of Sociology 981320 - 1350

Portes A, Zhou M, 1992, "Gaining the upper hand: economic mobility among immigrant and domestic minorities" Ethnic and Racial Studies 15491 - 522

Portes A, Zhou M, 1993, "The new second generation: segmented assimilation and its variants" Annals of the American Academy of Political and Social Sciences $53074-96$

Preston V, McLafferty S, Liu X F, 1998, "Geographical barriers to employment for American and immigrant workers" Urban Studies 35 529-545

Sampson R J, Morenoff J D, Gannon-Rowley T, 2002, "Assessing 'neighborhood effects': social processes and new directions in research" Annual Review of Sociology 28443 - 478

Sanders J, Nee V, 1996, "Immigrant self-employment: the family as social capital and the value of human capital" American Sociological Review 61231 -249

Smith C, 1995, "Asian New York: the geography and politics of diversity" International Migration Review $2959-84$

Tseng Y-F, 1995, "Beyond 'Little Taipei': the development of Taiwanese immigrant businesses in Los Angeles" International Migration Review 2933 - 58

Van der Klaauw B, van Ours J, 2003, "From welfare to work: does neighborhood matter?" Journal of Public Economics $87957-985$

Wacquant L, 1993, "Urban outcasts: stigma and division in the Black American ghetto and the French periphery" International Journal of Urban and Regional Research 17366 - 383

Waldinger R, 1995, “The 'other side' of embeddedness: a case-study of the interplay of economy and ethnicity" Ethnic and Racial Studies 18555 - 580

Waldinger R, 1996, "Ethnicity and opportunity in the plural city", in Ethnic Los Angeles Eds R Waldinger, M Bozorgmehr (Russell Sage Foundation, New York) pp 445-470

Waldinger R, 1997, "Black/immigrant competition re-assessed: new evidence from Los Angeles" Sociological Perspectives $\mathbf{4 0} 365-386$

Waters M C, 1996a, "Ethnic and racial identities of second-generation Black immigrants in New York City", in The New Second Generation Ed. A Portes (Russell Sage Foundation, New York) pp $171-196$

Waters M C, 1996b, "The impact of racial segregation on the education and work outcomes of second generation West Indians in New York City", WP 216, Jerome Levy Economics Institute of Bard College, Annandale-on-Hudson, NY

Wilson W J, 1987 The Truly Disadvantaged (University of Chicago Press, Chicago, IL)

Wilson W J, 1996 When Work Disappears (Alfred Knopf, New York)

Yoon In-Jin, 1995, "The growth of Korean immigrant entrepreneurship in Chicago" Ethnic and Racial Studies 18315 - 335 


\section{Appendix}

Table A1. Regression results for control variables in models, by gender, seven ethnic groups combined.

$B \quad \begin{aligned} & \text { Stan- } \\ & \text { dard } \\ & \text { error }\end{aligned}$

\section{Male}

(Constant)

$2.953 \quad 0.224$

$\begin{array}{rrrr}0.224 & 13.212 & 0.000 \\ 0.021 & -0.021 & -4.049 & 0.000\end{array}$

Number of 1995

Number of children (including $18+$ at home) 1995

Sick leave 1995

Preretired status $1995^{\mathrm{a}}$

Parental leave 1995

Studying full-time 1995

Number of children under 7 1999

Number of children (including $18+$ at home) 1999

Sick leave 1999

Preretired status 1999

Parental leave $1999^{\mathrm{b}}$

Studying full-time 1999

Number of children under 7 2002

Number of children (including $18+$ at home) 2002

Sick leave 2002

Preretired status 2002

Parental leave 2002

Studying full-time 2002

Years in Sweden (only immigrants) 1995

Age in 1995

Age $4-47(>50 \text { in } 1999)^{c}$

Education $=$ preschool

Education $=$ less than 9 years

Education $=9(10)$ years ${ }^{\mathrm{d}}$

Education $=$ less than 14 years $^{\mathrm{d}}$

Education $=14+$ years; not $\mathrm{PhD}$

$-0.085 \quad 0.02$

0.458

2.182

$\begin{array}{lllllll}0.032 & 0.013 & 0.016 & 2.518 & 0.012 & 0.306 & 3.268\end{array}$

$\begin{array}{rrrrrrr}0.050 & 0.039 & 0.005 & 1.294 & 0.196 & 0.870 & 1.149\end{array}$

$\begin{array}{lllllll}-0.692 & 0.087 & -0.041 & -7.944 & 0.000 & 0.486 & 2.059\end{array}$

$\begin{array}{rrrrrrr}0.524 & 0.039 & 0.053 & 13.470 & 0.000 & 0.803 & 1.245\end{array}$

$\begin{array}{lllllll}0.183 & 0.030 & 0.026 & 6.194 & 0.000 & 0.698 & 1.433\end{array}$

$\begin{array}{lllllll}-0.110 & 0.025 & -0.027 & -4.327 & 0.000 & 0.329 & 3.036\end{array}$

$\begin{array}{lllllll}0.059 & 0.017 & 0.028 & 3.441 & 0.001 & 0.191 & 5.229\end{array}$

$\begin{array}{lllllll}0.356 & 0.036 & 0.039 & 10.030 & 0.000 & 0.835 & 1.198\end{array}$

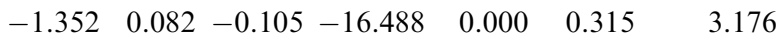

$\begin{array}{lllllll}0.546 & 0.038 & 0.059 & 14.486 & 0.000 & 0.761 & 1.315\end{array}$

$\begin{array}{lllllll}-0.319 & 0.032 & -0.040 & -9.854 & 0.000 & 0.763 & 1.310\end{array}$

$\begin{array}{lllllll}-0.170 & 0.026 & -0.040 & -6.604 & 0.000 & 0.345 & 2.903\end{array}$

$\begin{array}{lllllll}0.050 & 0.016 & 0.023 & 3.053 & 0.002 & 0.219 & 4.569\end{array}$

$\begin{array}{rrrrrrr}0.693 & 0.029 & 0.090 & 24.153 & 0.000 & 0.918 & 1.089\end{array}$

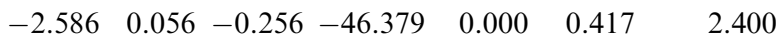

$\begin{array}{rrrrrrr}1.114 & 0.033 & 0.143 & 34.168 & 0.000 & 0.720 & 1.389\end{array}$

$\begin{array}{lllllll}-0.940 & 0.043 & -0.087 & -22.067 & 0.000 & 0.811 & 1.233\end{array}$

$\begin{array}{rrrrrrr}0.041 & 0.002 & 0.088 & 21.290 & 0.000 & 0.745 & 1.343\end{array}$

$\begin{array}{lllllll}-0.024 & 0.002 & -0.079 & -13.854 & 0.000 & 0.388 & 2.576\end{array}$

$\begin{array}{lllllll}-0.297 & 0.046 & -0.031 & -6.464 & 0.000 & 0.556 & 1.800\end{array}$

$\begin{array}{lllllll}-1.647 & 0.066 & -0.093 & -24.892 & 0.000 & 0.908 & 1.101\end{array}$

$\begin{array}{lllllll}-0.484 & 0.040 & -0.048 & -12.190 & 0.000 & 0.813 & 1.231\end{array}$

$\begin{array}{lllllll}-0.649 & 0.033 & -0.083 & -19.428 & 0.000 & 0.687 & 1.456\end{array}$

$\begin{array}{lllllll}0.440 & 0.048 & 0.038 & 9.152 & 0.000 & 0.720 & 1.388\end{array}$

$\begin{array}{lllllll}0.402 & 0.030 & 0.055 & 13.500 & 0.000 & 0.765 & 1.307\end{array}$

Education $=\mathrm{PhD}$ and licentiate

Education up from low $1995-99^{\mathrm{d}}$

$\begin{array}{rrrr}0.426 & 0.099 & 0.016 & 4.299\end{array}$

$\begin{array}{lll}0.000 & 0.964 & 1.037\end{array}$

Education up from medium $1995-99^{d}$

Education up from low $1999-2002^{d}$

Education up from medium $1999-2002^{\mathrm{d}}$

Changed from single to couple 1995-99

Changed from couple to single 1995-99

Changed from single to couple $1999-2002$

$\begin{array}{lllllll}-0.195 & 0.044 & -0.017 & -4.414 & 0.000 & 0.817 & 1.223\end{array}$

$\begin{array}{lllllll}0.106 & 0.073 & 0.006 & 1.456 & 0.145 & 0.777 & 1.286\end{array}$

$\begin{array}{lllllll}0.510 & 0.049 & 0.042 & 10.396 & 0.000 & 0.786 & 1.272\end{array}$

$\begin{array}{lllllll}0.238 & 0.068 & 0.013 & 3.494 & 0.000 & 0.849 & 1.178\end{array}$

$\begin{array}{lllllll}0.112 & 0.039 & 0.012 & 2.900 & 0.004 & 0.743 & 1.345\end{array}$

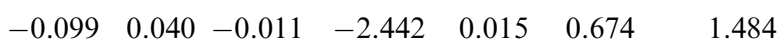

$\begin{array}{lllllll}0.285 & 0.042 & 0.027 & 6.825 & 0.000 & 0.782 & 1.278\end{array}$

$\begin{array}{llllllll}\text { Changed from couple to single } & -0.039 & 0.048 & -0.003 & -0.825 & 0.409 & 0.706 & 1.416\end{array}$ 1999-2002 
Table A1 (continued).

$B \quad \begin{aligned} & \text { Stan- } \\ & \text { dard } \\ & \text { error }\end{aligned}$

\section{Male}

Labour market average income 1999 100SEK

Labour market average income 2002

$\begin{array}{rrrrrrr}0.001 & 0.000 & 0.027 & 3.202 & 0.001 & 0.183 & 5.462 \\ 0.001 & 0.000 & 0.069 & 9.680 & 0.000 & 0.248 & 4.029 \\ 0.001 & 0.000 & 0.069 & 9.680 & 0.000 & 0.248 & 4.029 \\ 0.044 & 0.808 & 0.001 & 0.055 & 0.956 & 0.065 & 15.380 \\ -0.844 & 0.885 & -0.015 & -0.954 & 0.340 & 0.052 & 19.221 \\ -2.259 & 0.253 & -0.020 & -1.023 & 0.306 & 0.032 & 30.940 \\ 0.108 & 0.227 & 0.009 & 0.474 & 0.636 & 0.037 & 26.734 \\ 0.000 & 0.000 & -0.018 & -2.297 & 0.022 & 0.203 & 4.928 \\ 0.000 & 0.000 & -0.040 & -5.273 & 0.000 & 0.215 & 4.647 \\ 0.000 & 0.000 & -0.021 & -1.400 & 0.161 & 0.055 & 18.170 \\ 0.000 & 0.000 & 0.058 & 3.612 & 0.000 & 0.050 & 20.040 \\ 0.000 & 0.000 & 0.051 & 4.624 & 0.000 & 0.102 & 9.773 \\ 0.000 & 0.000 & -0.049 & 3.824 & 0.000 & 0.078 & 12.890 \\ & & & & & & \\ -1.132 & 0.472 & -0.020 & -2.398 & 0.016 & 0.180 & 5.559 \\ 0.830 & 0.660 & 0.012 & 1.257 & 0.209 & 0.135 & 7.395 \\ 4.707 & 3.835 & 0.016 & 1.227 & 0.220 & 0.079 & 12.714 \\ & & & & & & \\ 8.954 & 5.741 & 0.022 & 1.560 & 0.119 & 0.062 & 16.183 \\ & & & & & & \\ 1.199 & 1.323 & 0.020 & 0.906 & 0.365 & 0.025 & 39.300 \\ & & & & & & \\ -7.792 & 1.494 & -0.102 & -5.217 & 0.000 & 0.033 & 30.441 \\ & & & & & & \\ 0.604 & 0.011 & 0.207 & 56.997 & 0.000 & 0.961 & 1.041\end{array}$

Percentage own-ethnicity 1995

Percentage own-ethnicity 1999

Percentage immigrants in the environment 1995

Percentage immigrants in the environment 1999

Population density per $\mathrm{km}^{2} 1995$

Population density per $\mathrm{km}^{2} 1999$

Immigrant density per $\mathrm{km}^{2} 1995$

Immigrant density per $\mathrm{km}^{2} 1999$

Density 95 of own-ethnic group $/ \mathrm{km}^{2}$

Density 99 of own-ethnic group $/ \mathrm{km}^{2}$

Percentage unemployed in environment 1995

Percentage unemployed in environment 1999

Percentage own-ethnic $1995 \times$ percentage unemployed in environment 1995

Percentage own-ethnic $1999 \times$ percentage unemployed in environment 1999

Percentage immigrants in environment $1995 \times$ percentage unemployed in environment 1995

Percentage immigrants in environment $1999 \times$ percentage unemployed in environment 1999

Standardized residual male 
Table A1 (continued).

$B \quad \begin{aligned} & \text { Stan- } \\ & \text { dard } \\ & \text { error }\end{aligned}$

\section{Female}

(Constant) $\quad 4.055 \quad 0.252$

Number of children under age $7 \quad-0.437 \quad 0.023 \quad-0.111-18.690 \quad 0.000$ 1995

Number of children (including $18+$ at home) 1995

Sick leave 1995

Preretired status $1995^{\mathrm{b}}$

Parental leave 1995

Studying full-time 1995

Number of children under age 7 1999

Number of children (including $18+$ at home) 1999

Sick leave 1999

Preretired status 1999

Parental leave $1999^{\mathrm{c}}$

Studying full-time 1999

$\begin{array}{lllll}-0.003 & 0.013 & -0.001 & -0.218\end{array}$$$
\begin{array}{r}
0 \\
-0 \\
0 \\
0 \\
0 \\
0
\end{array}
$$$$
\begin{array}{rrr}
0.249 & 0.040 & 0.025
\end{array}
$$$$
6.175
$$$$
0.827 \quad 0.366
$$

$\begin{array}{llll}-0.599 & 0.084 & -0.039 & -7.136\end{array}$

$0.000 \quad 0.816$

$\begin{array}{llll}0.172 & 0.035 & 0.025 & 4.968\end{array}$

$0.000 \quad 0.475$

$\begin{array}{llllll}0.301 & 0.031 & 0.043 & 9.706 & 0.000 & 0.712\end{array}$

$\begin{array}{llllll}0.057 & 0.029 & 0.015 & 1.962 & 0.050 & 0.251\end{array}$

$\begin{array}{lllllll}0.048 & 0.019 & 0.022 & 2.601 & 0.009 & 0.196 & 5.094\end{array}$

$\begin{array}{rrrrrrr}0.524 & 0.036 & 0.061 & 14.557 & 0.000 & 0.784 & 1.275\end{array}$

$\begin{array}{rrrrrrr}-1.060 & 0.077 & -0.090 & -13.687 & 0.000 & 0.318 & 3.140 \\ 0.497 & 0.034 & 0.068 & 14.401 & 0.000 & 0.616 & 1.624\end{array}$

Number of children under age 7

$\begin{array}{llll}-0.102 & 0.032 & -0.014 & -3.204\end{array}$

$0.001 \quad 0.757$

1.322 2002

Number of children (including $18+$ at home) 2002

Sick leave 2002

Preretired status 2002

Parental leave 2002

Studying full-time 2002

Years in Sweden (only immigrants) 1995

Age in 1995

Age 4-47 (>50 in 1999) ${ }^{d}$

Education $=$ preschool

Education $=$ less than 9 years

Education $=9$ (10) years $^{\mathrm{e}}$

Education $=$ less than 14 years ${ }^{\mathrm{e}}$

$\begin{array}{llll}-1.120 & 0.032 & -0.261 & -35.541\end{array}$

$0.000 \quad 0.257$

3.889

$\begin{array}{lllllll}0.009 & 0.019 & 0.004 & 0.463 & 0.643 & 0.192 & 5.200\end{array}$

$\begin{array}{rrrrrrr}0.877 & 0.029 & 0.120 & 30.270 & 0.000 & 0.887 & 1.127 \\ -2.111 & 0.053 & -0.232 & -40.014 & 0.000 & 0.415 & 2.407 \\ 1.271 & 0.034 & 0.180 & 37.701 & 0.000 & 0.611 & 1.636 \\ -0.680 & 0.037 & -0.077 & -18.286 & 0.000 & 0.794 & 1.259 \\ 0.045 & 0.002 & 0.093 & 20.635 & 0.000 & 0.687 & 1.455\end{array}$

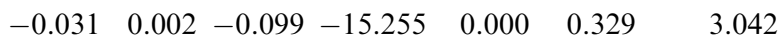

$\begin{array}{llllll}-0.745 & 0.054 & -0.074-13.830 & 0.000 & 0.486 & 2.056\end{array}$

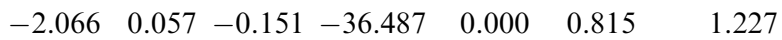

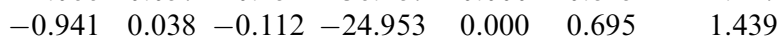

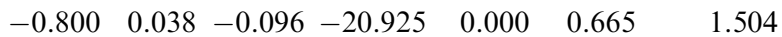

$\begin{array}{lllllll}0.385 & 0.063 & 0.028 & 6.105 & 0.000 & 0.676 & 1.478\end{array}$

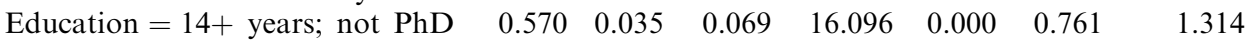

Education $=\mathrm{PhD}$ and licentiate $\quad \begin{array}{llllllll}1.113 & 0.199 & 0.021 & 5.596 & 0.000 & 0.989 & 1.011\end{array}$

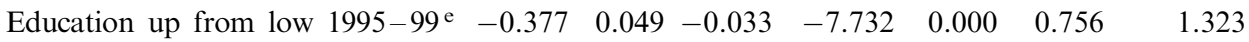

$\begin{array}{llllllll}\text { Education up from medium } & -0.008 & 0.079 & 0.000 & -0.104 & 0.918 & 0.718 & 1.393\end{array}$ $1995-99^{\mathrm{e}}$

Education up from low $1999-2002^{\mathrm{e}}$

Education up from medium $1999-2002^{\mathrm{e}}$

Changed from single to couple 1995-99

Changed from couple to single 1995-99

Changed from single to couple 1999-2002

Changed from couple to single 1999-2002

Labour market average income 1999 100SEK

$\begin{array}{rrrrrrr}0.895 & 0.052 & 0.073 & 17.299 & 0.000 & 0.780 & 1.281 \\ 0.300 & 0.070 & 0.018 & 4.298 & 0.000 & 0.806 & 1.240 \\ 0.210 & 0.047 & 0.018 & 4.440 & 0.000 & 0.893 & 1.120 \\ -0.195 & 0.038 & -0.021 & -5.191 & 0.000 & 0.857 & 1.166 \\ 0.259 & 0.049 & 0.021 & 5.240 & 0.000 & 0.890 & 1.124 \\ -0.224 & 0.047 & -0.019 & -4.752 & 0.000 & 0.904 & 1.107 \\ 0.000 & 0.000 & 0.015 & 1.584 & 0.113 & 0.164 & 6.087\end{array}$


Table A1 (continued).

$B \quad \begin{aligned} & \text { Stan- } \\ & \text { dard } \\ & \text { error }\end{aligned}$

\section{Female}

Labour market average income 2002

Percentage own-ethnicity 1995

Percentage own-ethnicity 1999

Percentage immigrants in the environment 1995

Percentage immigrants in the environment 1999

Population density per $\mathrm{km}^{2} 1995$

Population density per $\mathrm{km}^{2} 1999$

Immigrant density per $\mathrm{km}^{2} 1995$

Immigrant density per $\mathrm{km}^{2} 1999$

Density 1995 of own-ethnic group $/ \mathrm{km}^{2}$

Density 1999 of own-ethnic group $/ \mathrm{km}^{2}$

Percentage unemployed in environment 1995

Percentage unemployed in environment 1999

Percentage own-ethnic $1995 \times$ percentage unemployed in environment 1995

Percentage own-ethnic $1999 \times$ percentage unemployed in environment 1999

Percentage immigrants in environment $1995 \times$

$\begin{array}{rrrrrrr}0.001 & 0.000 & 0.044 & 5.478 & 0.000 & 0.216 & 4.629 \\ 2.071 & 0.926 & 0.035 & 2.237 & 0.025 & 0.058 & 17.144 \\ -2.712 & 0.945 & -0.045 & -2.869 & 0.004 & 0.055 & 18.060 \\ -0.044 & 0.293 & -0.003 & -0.151 & 0.880 & 0.030 & 33.305 \\ 0.228 & 0.261 & 0.017 & 0.871 & 0.384 & 0.036 & 27.959 \\ & & & & & & \\ 0.000 & 0.000 & -0.024 & -2.737 & 0.006 & 0.174 & 5.758 \\ 0.000 & 0.000 & -0.023 & -2.739 & 0.006 & 0.190 & 5.265 \\ 0.000 & 0.000 & 0.017 & 1.013 & 0.311 & 0.048 & 20.707 \\ 0.000 & 0.000 & 0.038 & 2.171 & 0.030 & 0045 & 22.120 \\ 0.000 & 0.000 & 0.003 & 0.210 & 0.834 & 0.089 & 11.208 \\ 0.000 & 0.000 & -0.031 & -2.250 & 0.024 & 0.072 & 13.911 \\ 0.713 & 0.550 & 0.012 & 1.296 & 0.195 & 0.168 & 5.949 \\ -0.118 & 0.767 & -0.002 & -0.154 & 0.878 & 0.127 & 7.896 \\ -3.955 & 4.163 & -0.013 & -0.950 & 0.342 & 0.078 & 12.808 \\ & & & & & & \\ 6.828 & 5.429 & 0.016 & 1.258 & 0.209 & 0.081 & 12.358 \\ & & & & & & \\ -0.319 & 1.520 & -0.005 & -0.210 & 0.834 & 0.024 & 41.640\end{array}$
unemployed in environment 1995

Percentage immigrants in environment $1999 \times$ unemployed in environment 1999

Standardized residual female

$\begin{array}{llllll}0.618 & 0.012 & 0.200 & 51.838 & 0.000 & 0.939\end{array}$

1.065

${ }^{a}$ VIF-variance inflation factor.

${ }^{b}$ Preretired status means that a person is recorded to have received an income from an official preretirement scheme handled by the Social Insurance office. This could be a part-time or a full-time preretirement status.

${ }^{\mathrm{c}}$ Sweden has the most comprehensive paid parental leave system in the world. Parents are entitled to 13 months of paid leave ( $80 \%$ of salary) after a child is born and another 3 months of a lower level of benefit. Fathers (or mothers) are obliged to use at least 2 of these 16 months; remaining time can be transferred to either parent. Hence, being on parental leave does not affect the income much but some effects are reasonable to expect.

${ }^{\mathrm{d}}$ Income varies with age so that the average income rises with age up to age 50, and then declines. We have introduced a dummy indicating if a person is above age 50 or not.

e The educational level of individuals is classified according to number of years in schooling. A low level means less than 11 years, a medium level is $12-13$ years, and a high level is 14 or more years in school. Upward educational transitions can thus be either from low to medium or high or from medium to high. 
Conditions of use. This article may be downloaded from the E\&P website for personal research by members of subscribing organisations. This PDF may not be placed on any website (or other online distribution system) without permission of the publisher. 